\title{
IMPLEMENTATION OF MAINTENANCE STRATEGIES IN THE LIFE CYCLE COSTING OF PRODUCT-SERVICE SYSTEMS
}

\author{
Schneider, Jannik Alexander (1); \\ Wurst, Johanna (1); \\ Gruetzmann, Ines (2); \\ Mozgova, Iryna (1); \\ Lachmayer, Roland (1) \\ 1: Leibniz University Hannover; \\ 2: Baker Hughes
}

\begin{abstract}
Estimating the costs of products during development to design a cost efficent product is a well established process. But in the case of Product-Service Systems estimating the costs of the individual product is not sufficent. Instead it is necessary to calculate the cost incured over the entire life cycle of the product. Because with Product-Service Systems the majority of costs is not incurred during manufacturing of the product but instead during the operation. One of the major cost components accruing during the operation of the product are the maintennace costs. Therefore, current life cycle costing models show the impoact of component design on the maintennace cost of the Product-Service System. But they do not show how different maintennace strategies that can have an impact on the overall life cycle costs of the Product-Service System. Thus, this paper shows a method for the implementation of different maintennace strategies into life cycle costing and applies it in an industrial use case.
\end{abstract}

Keywords: Product-Service Systems (PSS), Design costing, Decision making, Life Cycle Costing, Maintenance Strategy

\section{Contact:}

Schneider, Jannik Alexander

Leibniz University Hannover

Institut für Produktentwicklung und Gerätebau

Germany

schneider@ipeg.uni-hannover.de 


\section{INTRODUCTION}

When developing a product its costs are a major factor that influence the decisions made during development because a product that is too expensive usually doesn't survive in the market and retroactive changes to product design are much more expensive than those made in early phases of product design (Ehrlenspiel et al., 2007). This is not just true for conventional products but also for product-service systems (PSS). These PSS are business models that are not only based on the sale of a physical product but also on the sale of the service that can be provided with such a product (T. McAloone et al., 2011). Therefore when considering the costs of a PSS these cannot just be equated to the manufacturing costs but they also contain the costs of maintenance and operation (Johannknecht et al., 2016a; Gatzen M. et al., 2013). In the case of the PSS maintenance and operation usually exceed the initial manufacturing costs. Which means it is especially important to consider how design decisions affect the costs of the operation of the PSS. Additionally, PSS usually don't contain only a singular product but multiples of the same, also referred to as a fleet. Thus these costs are driven by the costs of the individual product but also by the costs of the entire fleet of products that are necessary to enable the PSS operator to provide the service to all customers that want to buy it (Schneider et al., 2020). As shown in Figure 1 the maintenance attributes of a product are major factor not just for the costs of the individual product but also in how many products are needed to provide the service in a timely manner to all interested customers. This difference in required fleet size to provide the service to customers directly impacts the initially required capital investment as well as the overall fleet maintenance costs. Which is different to comparing individual products, where the product with the lower costs is usually preferable. But in the case of a fleet the low cost product can have a lower availability which means a larger fleet is necessary resulting in an overall higher cost despite the lower individual cost.

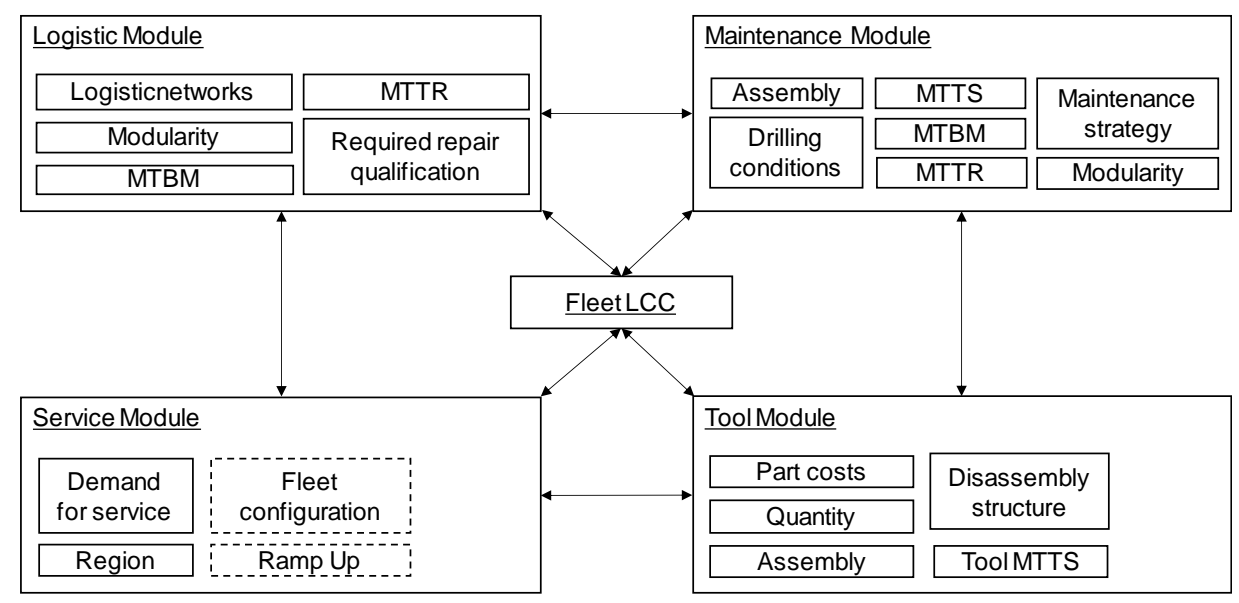

MTTR : Mean Time to Repair MTBM : Mean Time between Maintenance MTTS : Mean Time to Scrap

Figure 1. Interdependencies of parameters for fleet LCC of PSS (Schneider et al., 2020)

In existing models for calculating the life cycle costs of a PSS, the maintenance costs are calculated by utilising a mean time between maintenance value derived from a periodic maintenance strategy (Johannknecht et al., 2016b). But with the increased digitalization of products with concepts like the digital twin, being implemented by companies more frequently, the maintenance strategies employed by many companies change. Today the use of event-based maintenance strategies is more prevalent since the traditional difficulties that made the implementation of these strategies so rare can be mitigated by the aforementioned ideas. This makes it necessary for PSS life cycle costing models to implement ways to model these different maintenance strategies. Therefore this paper aims to answer the question how can different maintenance strategies be realised in life cycle costing models? Furthermore, it will show which aspects are needed to ensure that these results will meet the necessary requirements to make sure that these are compatible and provide the needed information for the calculation of the fleet size of the PSS. All this will be formalised in a method, which can be used to guide through this part of the life cycle costing process. Beginning with an explanation of the different maintenance strategies that are used today as well as the life cycle costing process. Subsequently he 
requirements for the method will be explained and then the method itself. Closing with an application of the method in an industry case study with Baker Hughes.

\section{BACKGROUND}

\subsection{Maintenance strategies}

According to the European maintenance standard DIN EN 31051, a maintenance strategy is defined as „combination of all technical and administrative actions [...] in the lifetime of a unit, in order to be in the fully functional state or to recover into this one, so that this unit can fulfil its requirements" (Merkt 2020). Thaduri and Famurewa (2020) generalize these assumptions and describe maintenance strategies as ,activities for retaining a system in an operating state or restoring it to a state that is considered necessary for it operation and utilization" (Thaduri and Famurewa, 2020).

Basically, the three components of repair, inspection and replacement can be identified within the divergent maintenance strategies (Liu et al., 2019). The former acts as a preventive measure to protect the loss of functionality, whereas an inspection is the constant observation of products before or after a failure (Liu et al., 2019). The latter, a replacement, is the immediate reaction to a significant deterioration in the level of functionality (Liu et al., 2019). An overview of the maintenance strategies in use today is given in Figure 2. Divided into reactive, proactive and knowledge-based approaches, a classification of the large number of maintenance strategies can also be made.

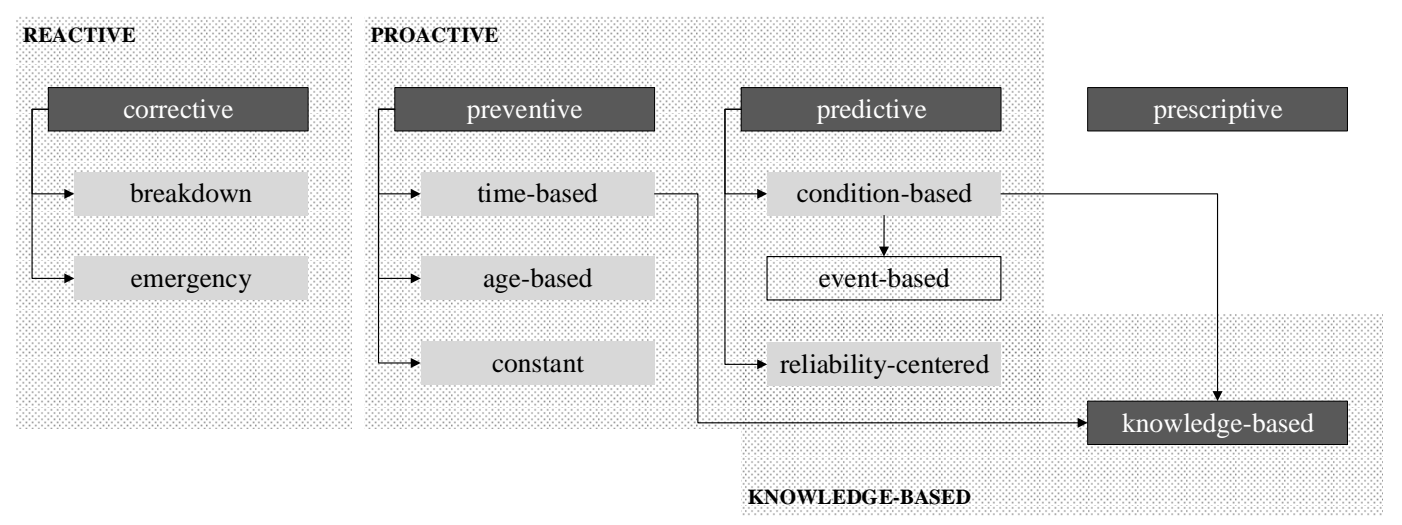

Figure 2. Overview of the classic and extended maintenance strategies

Based on the assumptions of Thaduri et al. (2020), four basic orientations can be identified known as corrective, preventive, predictive and prescriptive maintenance strategies. Moreover, further maintenance strategies like „total productive maintenance“, „lean maintenance“ or „knowledge-based maintenance" are discussed below. A corrective action is carried out after the system already failed and lost its functionality (Wenninghoff and Sandau, 2019; Ben-Daya, 2009; Thaduri and Famurewa, 2020; Pawellek, 2013; Liu et al., 2019).

The preventive approaches are based on the goal of maintaining functionality before an actual product failure (Wenninghoff and Sandau, 2019; Ben-Daya et al., 2000; Thaduri and Famurewa, 2020; Pawellek, 2013; Liu et al., 2019). According to Frederiksson (2012) preventive maintenance can be defined as „maintenance carried out at predetermined intervals or according to prescribed criteria and intended to reduce the probability of failure or the degradation of the functioning of an item." (Frederiksson and Larsson 2012). Three common preventive approaches relate to the timing of the maintenance intervals. The "age-based" and "time-based" as well as the "constant interval" maintenance strategy introduce measures based on fixed maintenance intervals (Wenninghoff and Sandau, 2019; Ben-Daya, 2009). A major challenge with these approaches is the attempt to find a balance between the high costs of short intervals and the high risk of long intervals (Ben-Daya, 2009; Ben-Daya et al., 2000). In contrast, the "aged-based" strategy provides for a product exchange after reaching a predefined product age (Ben-Daya et al., 2000; Liu et al., 2019).

In contrast to the preventive approaches, predictive maintenance strategies are based on the control of process parameters and the constant comparison of these with predefined tolerance limits. In this case, tolerance limits are used to estimate whether a product is about to fail or has already failed. In the case of event-based maintenance the operating conditions of the product are recorded and compared against 
predefined events which are indicators for approaching product failure. Overall predictive maintenance aims to predict the failure of a product based on recorded environment or product data. This principle of the centralized or decentralized recording of the process parameters is extended to the prescriptive maintenance with regard to the ability of independent maintenance (Thaduri and Famurewa, 2020; Liu et al., 2019). An aim of this strategy is to increase the ability of the product to monitor, detect errors, and predict and improve it (Thaduri and Famurewa, 2020). Thus the prescriptive maintenance also recommends actions the actions that should be taken to improve maintenance and reduce risks of unexpected failures.

With a view to the increasing digitization of processes as well as internal communication of the systems, the knowledge-based maintenance approach offers the possibility to combine different strategies with each other in order to derive targeted maintenance measures. In the form of a descriptive data collection, a diagnostic analysis of cause-effect relationships and predictive learning from historical data, holistic knowledge of all maintenance processes can arise (Ansari et al., 2019; Pawellek, 2013). These knowledge building processes can be expanded to include further strategic approaches in order to be able to create a holistic picture of the processes depending on the maintenance design. In this context, the "lean maintenance strategy" enables the maintenance measures to be adapted to the market with the aim of minimizing both cost and resource waste (Pawellek, 2013).

\subsection{Life cycle costing}

Life cycle cost (LCC) was initially developed for decision support in the US Department of Defence when making procurement decisions and remains in use until today (White and Ostwald, 1976). But today's usage of LCC as a measurement for economic costs of a product over its entire lifetime has expanded (Asiedu and Gu, 1998). In some cases it is used to support the tasks of portfolio managers or product developers for an early assessment of LCC during product development (2016b; Fabrycky and Blanchard, 1991). LCC is also prevalent in the construction industry (Bull, 1993; Goh and Sun, 2016; Salem et al., 2003). There are also industrial norms written on how to calculate LCC with the IEC 60050-191:2014 describing general approach towards LCC allowing the reader to gaining a general understanding on life cycle costs and different methods to determine them. Because these methods are not very specific it is necessary to adapt them to each use case as required. The models developed for the construction industry focus on immovable assets, since this is not predetermined in the case of PSS the IEC 60050-191:2014 is cannot be directly applied. But there are already models that focus on PSS particularly on use and result oriented version. One of these is the model developed by Johannknecht (Johannknecht et al., 2019; Johannknecht et al., 2016a). Johannknecht divides the lifecycle costs into two distinct areas: capital expenditure (capex) which are mainly the initial production costs and operational expenditures (opex) which are the costs occurring during operation like material costs, labour costs and third-party costs (Johannknecht et al., 2016b). As shown in Figure 3, these costs are then further divided into wear parts, consumable parts, maintenance, repairs, external repairs and external inspections.

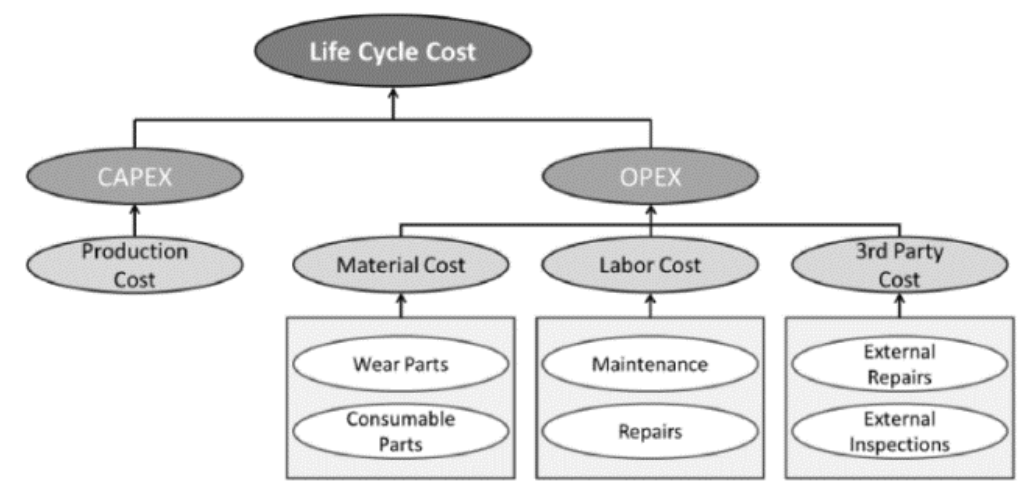

Figure 3. LCC composition (Johannknecht et al., 2016b)

The LCC of the product is then calculated as: The sum of capital expenditure plus operational expenditure, times the total time of use. For the calculation of the six components Johannknecht has defined (2018) six equations. Two of which are shown here: 


$$
\begin{aligned}
& \text { Maintenancecost }=\sum_{x=1}^{n} \frac{\text { Time for maintenance of component } x * \text { labour cost }}{\text { maintenance intervall of component } x} \\
& \text { Repairscost }=\sum_{x=1}^{n} \frac{\text { Time for repair of component } x * \text { quantity } * \text { labour cost }}{\text { repair intervall of component } x}
\end{aligned}
$$

For all of these inspections it is necessary to have a time interval that describes the frequency with which the individual costs occur. These frequencies are available if a preventive maintenance strategy is employed but there are no methods defined in these LCC calculations that describe how predictive maintenance strategies can be taken into consideration when calculating life cycle costs.

\section{REQUIREMENTS}

In order to determine the requirements of an approach that will enable the calculation of maintenance cost in a PSS regardless of the employed maintenance strategy it is necessary to look into the possible maintenance strategies and the requirements that stem from the LCC calculation of the PSS.

The requirements for LCC are driven by the cost's calculations for the opex as shown in Figure 3 and their corresponding equations. As the replacement or repair of a singular part can occur more than once over the lifetime of a product a cyclical approach to which repeats itself over the lifetime of the PSS is necessary. Furthermore, there is a need for secondary maintenance triggers, which cause a maintenance when adjacent components get maintained and therefore the repair or replacement of additional component is possible. Thus, there will be two maintenance triggers one based on the initial maintenance strategies and the second one based on adjacency and possible secondary requirements to ensure that no recently maintained or repaired components do no get replaced. If considering not just a singular product PSS but the entire fleet of products within the PSS as proposed in Figure 1 by Schneider et al. (2020) additional information about the product is required to calculate the costs of the PSS. Most importantly the ability to exchange entire subassemblies during maintenance which can drastically reduce repair times and lead to a different approach in how the MTBM of the individual modules and the components within must be tracked. In order to ensure that the maintenance information can be used for the calculation of system availability as proposed in Schneider et al. (2019) it is important that the information about the frequency of maintenance and time to repair can be seen as the established metrics meantime between maintenance (MTBM), meantime to repair (MTTR) and meantime to scrap (MTTS). This means that the following information are necessary to calculate either the individual costs of maintenance for a product in the PSS or for the calculation of costs that impact the entire fleet of product within the PSS:

- Mean time between maintenance;

- Mean time to repair;

- Mean time to scrap;

- Secondary maintenance triggers;

- Ability to swap modules.

When looking at the different maintenance strategies it is apparent that especially the preventative maintenance strategies can easily provide these measures since they are based on fixed repeating intervals which can be directly used as the required information for the MTBM and MTBM. While the other two orientations proactive and corrective appear to have no fixed maintenance intervals. Therefore, it is necessary to develop a method which allows to equate the information available in these strategies to MTBM and MTTS values so that they can be used in LCC. This means that it is necessary to have a method that describes how the different values required for the LCC of PSS can be derived for all the possible strategies that can be employed when operating a PSS.

\section{METHOD}

As explained in the previous section the main challenge lies within determining the MTBM and MTTS values for the components that are maintained using a predictive or corrective maintenance strategy. Therefore, the steps necessary for the implementation of these strategies into LCC will be elaborated further. In both cases it will be necessary to have access to data that will help to determine 
the actual frequencies that will occur for those components under the given strategy. This results, as shown in Figure 4, in four additional steps that need to be performed to determine the required values. As the bottom side showing the steps necessary for preventive maintenance strategies is setting MTBM and MTTS values equal to their corresponding strategy values it will not be further elaborated. Instead, the focus is on the top side for the predictive and corrective maintenances.

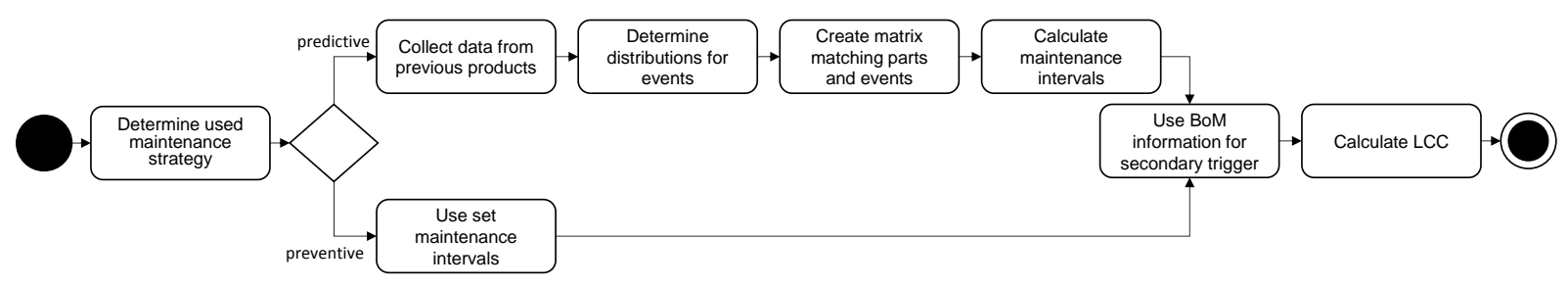

Figure 4. Method for determining maintenance information for LCC

For their implementation additional data is required and can be most likely sourced in the form of information gathered during the use phases of previous product generations. Alternatively, in some cases there might even be publicly accessible data that can be used to determine the MTBM and MTTS of products in development. The most important tasks when sourcing this data are ensuring that the quality of the data is not compromised and that it is transferable to the new product generation. This means in many cases it makes sense to look at environmental data that impact the product and how much time the product spends in the environment. For example, in the oil and gas drilling industry this could be temperature while drilling which impacts the lifetime of electrical components due to the fact that long times in high temperature can damage the soldering bonds and therefore lead to failures. In this case the condition and subsequently the reliability of the component degrade with the time it spends in high temperatures. In case of the corrective maintenance, similar components from previous generations can be used to estimate the lifetime of components.

In the next step it is necessary to determine with what probability an event that will trigger a maintenance after a certain amount of time. For this the data gathered during the use of the different products will be used. In order to have the largest possible sample size it is important to not only consider products that have recorded at least one event occurrence but also consider product which still have no events recorded. In order to determine the probability of an event occurring after a certain time several methods can be utilised like the Cox-Proportional-Hazard-Model, Kaplan-Meier estimator or a modified version of the maximum likelihood function to estimate the parameters of a function that best represents the probability of an event occurrence over time. When large amounts of data are available the use of modified maximum likelihood function will yield results of sufficient quality and is easily implemented into an automated program. As mentioned, it is necessary to considered data where the event has occurred but also data where the event hasn't occurred at the time of analysis. Which means that the maximum likelihood function must be modified to reflect this. This results in Equation 3 which can now reflect the quality of the function parameters chosen to match the function to the real events. For uncensored data the density of the function $f_{\theta}(t)$ is used and in the case that the event hasn't occurred the survival function $R_{\theta}(t)$ is used. With $\theta$ being the specific parameter for that function or parameter combination, while $t$ represents the timepoint for the point of realisation. This then leads to a distribution showing the probability of the event occurring over time as shown in Figure 5.

$$
l_{t_{1}, \ldots, t_{n}}=\sum_{i=1}^{n}\left(\delta_{i} \ln f_{\theta}\left(t_{i}\right)+\left(1-\delta_{i}\right) \ln R_{\theta}\left(t_{i}\right)\right)
$$

With this it is possible to estimate the probability of an event occurring after a given amount of time. Additionally, it allows to vary the probability with which the event occurrence is estimated allowing for more optimistic or conservative cost estimations. It is also very important to consider whether the probabilities of different can be considered cumulatively or if they have to be considered separately. Because in some cases they can be not independent from each other.

The next step is matching the individual event probabilities with the components that must be maintained after a given event. Based on this a table is created, as depicted in Figure 5., that shows which events and components trigger what maintenance actions. Based on this and the decision on how conservative the estimate is meant to be, a list can be created with MTBM and MTTS values for all components in a product. After these values are available, they have to be combined into clusters to 
generate the maintenance intervals for the product. When generating the cluster, the number of clusters can have a significant impact on the cost of the product since it directly impacts the availability of the given product. But it also affects how efficiently the lifetime of these components is used. Because the maintenance intervals cannot be optimal for every single component.
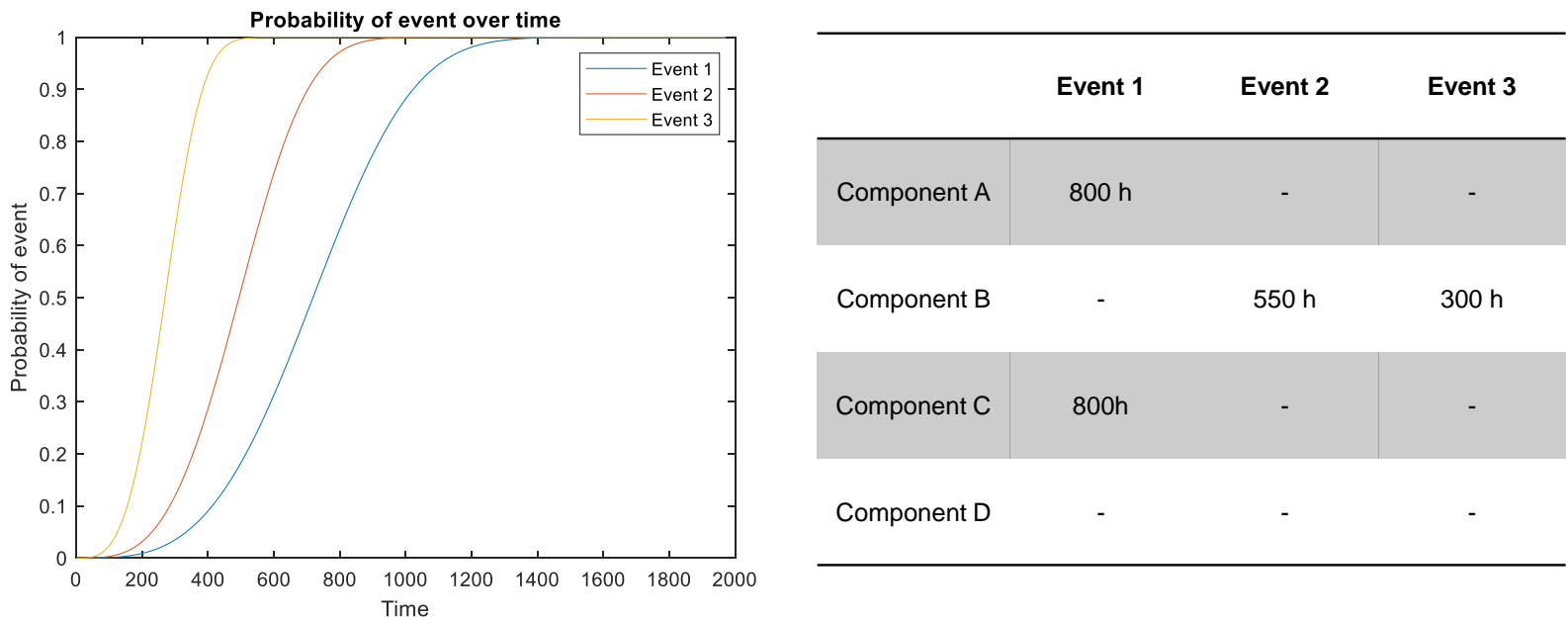

Figure 5. Event probability and repair timetable

With those maintenance intervals available for the LCC calculation the next step is to implement secondary maintenance triggers based on the assembly/disassembly structure of the product to ensure that components with similar lifetimes get maintained with each other to reduce the need for disassembly and reassembly reducing costs and increasing availability. This must be modelled here since it is expected that the organisation performing the maintenance will do so as well. To do this all components that are in the same position in the assembly structure have to be evaluated with their lifetime against the cost of an additional maintenance. This can be done using Equation 4 to evaluate whether the earlier maintenance with a different component is beneficial to the overall maintenance costs of the product.

$$
\mathrm{c}_{\mathrm{am}}>\mathrm{c}_{\text {value }} *\left(\mathrm{MTBM}_{\text {comp_ }_{-}}-\text {MTBM }_{\text {comp_y }_{-}}\right)
$$

In the case that the cost for an additional maintenance $c_{a m}$ is greater than the remaining value of the component undergoing maintenance the premature maintenance of the component will not be considered. In the opposite case the maintenance interval of component two will be adjusted to match the maintenance interval of component one. After all the previous calculations have been performed the resulting maintenance intervals in combination with the necessary maintenance steps can be used to calculate the LCC of a PSS as outlined in section 2.2.

\section{CASE STUDY}

The case study has been created in cooperation with Baker Hughes, who is an energy technology company. They operate oil and gas drilling equipment as a result-based PSS, which collect data that can be used to implement an event-based maintenance strategy. This strategy must be accurately represented in their LCC to ensure the costs of the finished product will match with those utilized in the business case for the product. The previously described method has been tested with products in development. The results shown here have been altered to protect Baker Hughes trade secrets. But the actual results are known to the authors and the changes did not alter the overall meaning of the results. In order to illustrate the necessity to distinguish between different maintenance strategies the method was applied on the same product once with an event-based maintenance strategy and once with a timebased maintenance strategy.

When using a time-based maintenance strategy, the maintenance costs of the product totals 31.8 dollars per hour. The base of hours is chosen because other costs components that for determining the cost of service are calculated per hour as well. The bill of material (BoM) for the tool in consideration here is analysed by maintenance engineers who give their expert opinion on the estimated MTBM of the individual components. With these estimated MTBMs and the costs for the maintenance and replacement of the 
components a cost per hour can be calculated for each. This can be seen in Figure 6. where some of the cost with their MTBM are shown the summation of these costs is what results in the overall maintenance costs of 31.8 dollars per hour. Furthermore, minimum and maximum values are given for the MTBM to allow for the calculation of best- and worst-case scenarios of the maintenance cost.

\begin{tabular}{|c|c|c|c|c|c|c|}
\hline part name & quantity & MTBM & $\begin{array}{c}\text { MTBM } \\
\text { min. }\end{array}$ & $\begin{array}{c}\text { MTBM } \\
\text { max. }\end{array}$ & Cost per part & Total Cost \\
\hline TOOL & 0 & & & & & \\
\hline PARTS,STANDARD & 0 & & & & & \\
\hline COMPONENTA & 1 & $2.250 \mathrm{H}$ & $1.500 \mathrm{H}$ & $3.000 \mathrm{H}$ & $0,92 \$ / H$ & $0,92 \$ / H$ \\
\hline COMPONENT B & 1 & $750 \mathrm{H}$ & $500 \mathrm{H}$ & $1.000 \mathrm{H}$ & $1,44 \$ / H$ & $1,44 \$ / H$ \\
\hline COMPONENT C & 1 & $2.250 \mathrm{H}$ & $1.500 \mathrm{H}$ & $3.000 \mathrm{H}$ & $1,03 \$ / H$ & $1,03 \$ / H$ \\
\hline COMPONENT D & 1 & $750 \mathrm{H}$ & $500 \mathrm{H}$ & $1.000 \mathrm{H}$ & $0,81 \$ / H$ & $0,81 \$ / H$ \\
\hline COMPONENTE & 1 & $1.200 \mathrm{H}$ & $1.000 \mathrm{H}$ & $1.400 \mathrm{H}$ & $0,18 \$ / H$ & $0,18 \$ / H$ \\
\hline COMPONENT F & 1 & $1.200 \mathrm{H}$ & $1.000 \mathrm{H}$ & $1.400 \mathrm{H}$ & $0,17 \$ / H$ & $0,17 \$ / \mathrm{H}$ \\
\hline COMPONENT G & 1 & $750 \mathrm{H}$ & $500 \mathrm{H}$ & $1.000 \mathrm{H}$ & $0,34 \$ / H$ & $0,34 \$ / H$ \\
\hline
\end{tabular}

Figure 6. Time-based maintenance strategy (excerpt)

For the calculation of the event-based maintenance costs data from the drilling conditions and data from the operation of older products can be utilised. This data is collected for all global operations of drilling equipment. If a product is developed with only a specific market in mind the data would now have to be filtered accordingly. In this case a global use of the PSS is planed which means that no further filtration of the data is necessary. Five distinct events are defined which impact the state of the product and therefore should trigger a maintenance. The first two events are temperature limits greater than $120^{\circ} \mathrm{C}$ and $200^{\circ} \mathrm{C}$ because these temperatures can impact the function of electrical components. Events three trough five are pressure above $5 \mathrm{MPa}$, solid contents in drilling mud greater than $5 \%$ for more than 100 hours and torque greater than $5000 \mathrm{Nm}$. These three events are mainly indicators for damage to external and structural components. For this the time until a product encounters any of the given events is recorded. Since not all products necessarily encounter the given events during their possibly still ongoing life it is necessary, as described in section 4, to consider this when fitting a function.

With this matching Weibull distributions can be obtained for each of the events and can then be used to determine the characteristic times until the event occurs as shown in Figure 7. These estimates can be taken at lower probabilities for a more conservative or at higher probabilities for a more optimistic estimation of event occurrence.

Table 1. Events and characteristic times matched to components (excerpt)

$\begin{array}{llllll} & \text { Event 1 } & \text { Event 2 } & \text { Event 3 } & \text { Event 4 } & \text { Event 5 } \\ \text { COMPONENT A } & - & - & - & - & 2.906 \mathrm{H} \\ \text { COMPONENT B } & - & - & 2.182 \mathrm{H} & 976 \mathrm{H} & - \\ \text { COMPONENT C } & - & - & - & - & 2.906 \mathrm{H} \\ \text { COMPONENT D } & - & - & - & - & - \\ \text { COMPONENT E } & - & - & 2.182 \mathrm{H} & - & 2.906 \mathrm{H} \\ \text { COMPONENT F } & 308 \mathrm{H} & 1.734 \mathrm{H} & - & - & - \\ \ldots & \ldots & \ldots & \ldots & \ldots & \ldots\end{array}$

These characteristic times from the Weibull distributions in Figure 7. are than matched to the events and components shown in Table 1. depending on which event impacts the state of which component. In some cases, this is not relevant or can be omitted since the assembly structure would result in the maintenance of that component when the maintenance for the other component is triggered. In this case the events one and four trigger a lower level maintenance in which only minor work and inspections are performed. While the other events trigger inspections as well but are expected to result in more extensive maintenance activities. After the initial pass the maintenance intervals for the event-based maintenance are every 300 hours and an additional one every 1700 hours. After this all components that contribute to the additional maintenance must be evaluated in accordance with Equation 4. For example, the Component $\mathrm{F}$ has a residual value of 132 dollars after 1500 hours $(5 * 300$ hours) at which time a maintenance would naturally happened, because of the 300 hour repeating maintenance interval. Comparing the residual value with the costs, of 450 dollars, that are incurred by performing an additional maintenance 200 hours later at the 1700 hour mark shows that the additional costs are higher than the used residual value. 


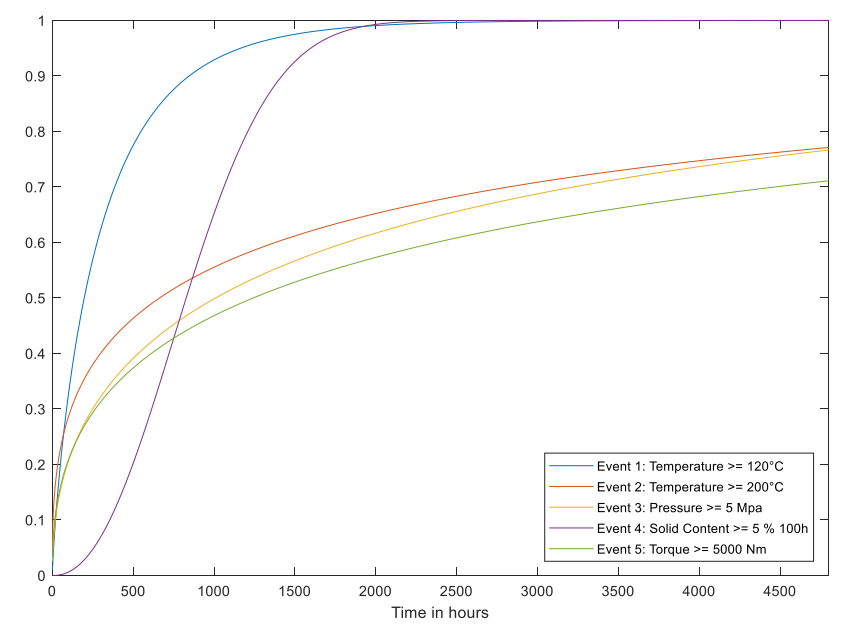

Figure 7. Weibull distributions for events

Therefore, a reduction of the maintenance interval for the connector is possible here which would bring it in line with the 300 hour interval. This holds true for the other components as well which allows for a singular maintenance interval that occurs every 300 hours. With the maintenance interval defined and the frequencies of the individual repairs and maintenance tasks know it is now possible to calculate the maintenance costs for the LCC. In this case the overall maintenance costs of the PSS product are reduced to 28.7 dollars per hour. With this the event-based maintenance strategy is already providing lower maintenance costs and therefore a reduction in LCC, but this also brings advantages for the required fleet size of the PSS since there is a reduction in maintenance frequency. While the event-based maintenance will likely occur every 300 hours. The time-based maintenance has a planned maintenance interval of every 250 hours. This means that over a lifetime of 4800 hours the PSS with the time-based maintenance strategy would have three maintenance visits more than the event-based maintenance strategy. Leading to lower product availability and therefore requiring a larger fleet for the same number of customers. Which in turn means that the individual costs for the service would increase. This shows that the maintenance strategy is a viable design variable to reduce the LCC of a PSS.

\section{DISCUSSION AND CONCLUSION}

It is important to model the maintenance costs in the cost calculations because the PSS development must focus on the LCC of a product and not only on the manufacturing costs. Especially modelling different maintenance strategies in these cost calculations is important since the choice of maintenance strategy remains with the operator and can be an important part of PSS design. Because as shown in section 5 the use of different maintenance strategies can have a significant impact on the maintenance cost of PSS and should therefore be represented as accurately as possible in any LCC calculation. This allows for a larger possible solutions space during the engineering design process when trying to design a cost effective PSS, because this way not only changes to the physical product are represented in the cost but also how they interact with different versions of the service component in the PSS. Furthermore, there is an additional cost impact when considering the entire product fleet in the PSS because of the differences in availability of individual products created by the different maintenance strategies.

This and the resulting effects on the logistics network required for the operation of a PSS should be investigated in future research. Furthermore, it should be evaluated how the necessary data can be collected and integrated into a process for the development of new products. For this the integration of the LCC process into existing frameworks like the technical inheritance (Mozgova et al., 2017; Lachmayer et al. 2015) is a possibility that should be explored. This can also help with better implementing the LCC process in the development of new product generations.

While the first test with the use case is promising, there is further need for validation especially when applying the proposed method to other use cases. The overall method is general enough to be applicable to a variety of use cases, the specific methods used for the calculations might have to be adapted. The presented method is certainly limited when predictive maintenance strategy is planned for an entirely new product that has no predecessors which can be used to determine the expected maintenance intervals for the predictive maintenance strategy. 


\section{ACKNOWLEDGMENTS}

This research is supported by Baker Hughes. The funding and valuable industry insights, into the use of life cycle costing for product-service systems, are greatly appreciated.

\section{REFERENCES}

Ansari, F., Glawar, R. and Nemeth, T. (2019), "PriMa: a prescriptive maintenance model for cyber-physical production systems", International Journal of Computer Integrated Manufacturing, Vol. 32 No. 4-5, pp. $482-503$

Asiedu, Y. and Gu, P. (1998), "Product life cycle cost analysis: State of the art review", International Journal of Production Research, Vol. 36 No. 4, pp. 883-908.

Ben-Daya, M. (2009), Handbook of maintenance management and engineering, Springer, London.

Ben-Daya, M., Duffuaa, S.O. and Raouf, A. (Eds.) (2000), Maintenance, Modeling and Optimization, Springer US, Boston, MA, s.l.

Bull, J.W. (Ed.) (1993), Life cycle costing for construction, 1. ed., Blackie Academic \& Professional, London.

Ehrlenspiel, K., Hundal, M.S., Kiewert, A. and Lindemann, U. (2007), Cost-Efficient Design, Springer-Verlag Berlin Heidelberg, Berlin, Heidelberg.

Fabrycky, W. and Blanchard, B. (1991), "Life Cycle Cost and Economic Analysis".

Gatzen M., Pemberton R., Peters V. and Krueger S. (2013), “A holistic design for excellence model based on life cycle costing and design scorecards".

Goh, B.H. and Sun, Y. (2016), "The development of life-cycle costing for buildings", Building Research \& Information, Vol. 44 No. 3, pp. 319-333.

Johannknecht, F. (2018), Lebenszyklusorientiertes Kostenmanagement für Produkt-Service Systeme: Dissertation, Berichte aus dem iPeG, 2017, Band 5, PZH Verlag, Garbsen.

Johannknecht, F., Gatzen, M.M., Hahn, D. and Lachmayer, R. (2016a), "Holistic Life Cycle Costing Approach for Different Development Phases of Drilling Tools", in International Petroleum Technology Conference, 2016-11-12, Bangkok, Thailand, International Petroleum Technology Conference.

Johannknecht, F., Gatzen, M.M. and Lachmayer, R. (2016b), "Life Cycle Cost Model for Considering Fleet Utilization in Early Conceptual Design Phases", Procedia CIRP, Vol. 48, pp. 68-72.

Johannknecht, F., Herrmann, M. and Lachmayer, R. (2019), "Kostenmanagement von Produkt-ServiceSystemen. Managing Costs of Product-Service Systems", Die Konstruktion, No. 6.

Lachmayer, R., Mozgova, I., Gottwald, P. (2015), "Formulation of Paradigm of Technical Inheritance", Proceedings of the 20th International Conference on Engineering Design (ICED15), Milan, Italy, 27.-30.07.2015

Liu, B., Lin, J., Zhang, L. and Kumar, U. (2019), “A Dynamic Prescriptive Maintenance Model Considering System Aging and Degradation”, IEEE Access, Vol. 7, pp. 94931-94943.

Pawellek, G. (2013), Integrierte Instandhaltung und Ersatzteillogistik: Vorgehensweisen, Methoden, Tools, Springer Vieweg, Berlin.

Mozgova, I., Barton, S., Demminger, C., Miebach, T., Taptimthong, P., Lachmayer, R., Nyhuis, P., Reimche, W., Wurz, M. C. (2017), "Technical Inheritance: Information basis for the identification and development of product generations", Proceedings of the Design Society: International Conference on Engineering Design, Vol. 6 Design Information and Knowledge, pp. 091-100.

Salem, O., AbouRizk, S. and Ariaratnam, S. (2003), "Risk-based Life-cycle Costing of Infrastructure Rehabilitation and Construction Alternatives", Journal of Infrastructure Systems, Vol. 9 No. 1, pp. 6-15.

Schneider, J.A., Gatzen, M.M. and Lachmayer, R. (2020), "The importance of considering fleet size in the lifecycle cost analysis of product service systems", Proceedings of the Design Society: DESIGN Conference, Vol. 1, pp. 1365-1374.

Schneider, J.A., Mozgova, I. and Lachmayer, R. (2019), “An Approach for Choosing the Cost Effective Design for a Product-Service System While Maintaining its Desired Reliability", Proceedings of the Design Society: International Conference on Engineering Design, Vol. 1 No. 1, pp. 3041-3050.

T. McAloone, Krestine Mougaard, L. Neugebauer, T. Nielsen and N. Bey (2011), "Orthogonal views on product/service-system design in an entire industry branch".

Thaduri, A. and Famurewa, S.M. (2020), "Evolution of Maintenance Processes in Industry 4.0", in Dima, I., Martinetti, A., Demichela, M. and Singh, S. (Eds.), Applications and Challenges of Maintenance and Safety Engineering in Industry 4.0, IGI Global, pp. 49-69.

Wenninghoff, N. and Sandau, A. (2019), "Agentensystem zur Steigerung der Betriebsbereitschaft automatisierter Fahrzeuge”, in Marx Gómez, J., Solsbach, A. and Klenke, T. (Eds.), Smart Cities/Smart Regions Technische, wirtschaftliche und gesellschaftliche Innovationen: Konferenzband zu den 10. BUIS-Tagen, 1st ed. 2019, pp. 325-338.

White, G.E. and Ostwald, P.F. (1976), "Life cycle costing”, Management accounting, Vol. 57 No. 7, pp. $39-42$. 